\title{
Dynamics of an Equatorial River Plume: Theory and Numerical Experiments Applied to the Congo Plume Case
}

\author{
CLÉMENT VIC \\ Laboratoire de Physique des Océans, UMR6523, UBO/IFREMER/CNRS/IRD, Brest, France \\ HENRICK BERGER \\ Actimar, Brest, France \\ ANNE-MARIE TrÉGUIER AND XAVIER COUVElARD \\ Laboratoire de Physique des Océans, UMR6523, UBO/IFREMER/CNRS/IRD, Brest, France
}

(Manuscript received 14 June 2013, in final form 18 October 2013)

\begin{abstract}
The Congo River has the second largest rate of flow in the world and is mainly responsible for the broad tongue of low-salinity water that is observed in the Gulf of Guinea. Despite their importance, near-equatorial river plumes have not been studied as thoroughly as midlatitude plumes and their dynamics remain unclear. Using both theory and idealized numerical experiments that reproduce the major characteristics of the region, the authors have investigated the dynamics of the Congo River plume and examine its sensitivity to different forcing mechanisms. It is found that near-equatorial plumes are more likely to be surface trapped than midlatitude plumes, and the importance of the $\beta$ effect in describing the strong offshore extent of the lowsalinity tongue during most of the year is demonstrated. It is shown that the buoyant plume constrained by the geomorphology is subject to the $\beta$ pulling of nonlinear structures and wavelike equatorial dynamics. The wind is found to strengthen the intrinsic buoyancy-driven dynamics and impede the development of the coastal southward current, in coherence with observations.
\end{abstract}

\section{Introduction}

The outflow of the Congo River is the second largest in the world with a mean rate of flow of about $40000 \mathrm{~m}^{3} \mathrm{~s}^{-1}$ (Dai and Trenberth 2002). As such, it is a major contributor to the mean state and the variability of the surface salinity in the Gulf of Guinea (Signorini et al. 1999), and it has been recently shown that it may have a strong impact on climate variability in the region (Materia et al. 2012). Moreover, rivers are important sources of carbon in the ocean (Schlünz and Schneider 2000), and the Congo River is one of the greatest contributors (Coynel et al. 2005). Its signature can be seen very far offshore of the river mouth (Hopkins et al. 2013) as highlighted by Fig. 1, which presents the sea surface salinity (SSS) and the colored,

Corresponding author address: Clément Vic, Laboratoire de Physique des Océans, 6 Avenue Victor Le Gorgeu, 29200 Brest, France.

E-mail: clement.vic@univ-brest.fr dissolved, and detrital organic matter (CDM) absorption length in the Gulf of Guinea. CDM, which is well correlated with SSS, has been demonstrated to be a useful indicator of the trophic chain and has been successfully used to track the Amazon River plume (Salisbury et al. 2011).

Despite its importance, the Congo River plume dynamics has not been much studied. Even if the role of environmental factors such as the geomorphology, the wind, and the ambient currents have been recently assessed in a realistic model (Denamiel et al. 2013, hereafter D13), the strong northwestward offshore extent of the low-salinity waters during most of the year remains misunderstood. Indeed, it is not a common feature as it opposes the predicted extent of the coastal current in the direction of the coastal Kelvin wave propagation (Chao 1988a) and is abnormally large [reaching $850 \mathrm{~km}$ according to Hopkins et al. (2013)]. Many theoretical (Yankovsky and Chapman 1997; Nof and Pichevin 2001) and numerical studies (Chao and Boicourt 1986; Chao 1988a; Kourafalou et al. 1996; Garvine 1999; Schiller 

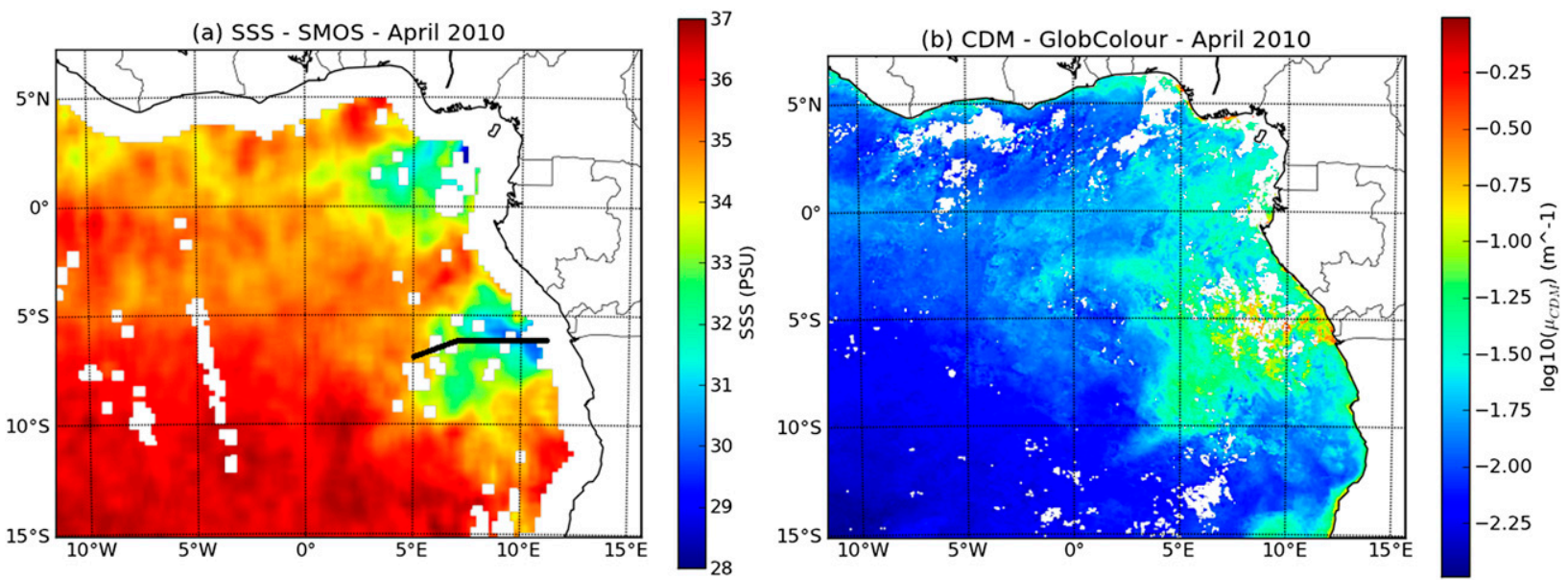

FIG. 1. Satellite visualizations of the Congo plume at the same date (mean over April 2010) during the period of the largest spread of the plume. The Congo mouth is at $6^{\circ}$ S. (a) The SSS from Soil Moisture Ocean Salinity (SMOS); the black line represents the section along which the BIOZAIRE section is drawn in Fig. 2. (b) The CDM absorption length scale from GlobColour data.

and Kourafalou 2010) have described the dynamics of midlatitude river plumes and the associated mechanisms of advection and diffusion of freshwater in the unforced case. They have also evaluated the impact of external forcing such as the wind or the bottom topography on plumes. Nonetheless, no study is dedicated to low-latitude river plumes, and the Congo River mouth position, where $f$ is very low and its gradient $\beta$ is at its maximum, could play a role in the self-induced buoyancy dynamics of the outflow.

Parallel to D13, we have carried out research on the Congo plume with a different strategy. We have situated the Congo River in a theoretical framework in order to predict what could be the dynamics of a near-equatorial plume in an unforced case and explore its fate at longer time scales. Then, we have used idealized numerical experiments to verify our theoretical assumptions and clarify the near-equatorial specific characteristic. Making the study more complex step by step, some sensitivity experiments have been carried out to estimate the impact of the geomorphology (bottom topography and coastline) and the wind on the plume.

In this paper, we aim to provide a new physical explanation for the northwestward extent of the Congo plume. We first describe what is the expected dynamics and morphology of the Congo plume by interpreting some nondimensional numbers associated with the problem in a physical parameter space. After a description of the model and the configuration used, we then discuss the impact of Earth's rotation on the plume as well as other forcings. Finally, we draw the main conclusions on the dynamics of near-equatorial plumes and discuss our results within the context of the realistic study of D13.

\section{Theoretical framework}

In this section, we review some theoretical and numerical studies that are relevant to near-equatorial river plumes. We also develop a theory of the Congo plume based on the dichotomous distinction of surface-trapped and bottom-influenced plumes made by Yankovsky and Chapman (1997), and then incorporate the major results of Garvine (1999) that reveal the importance of the physical and geometrical parameter range in the nearfield dynamics of river plumes. As the Congo River inflow is very important in comparison with standard values of midlatitudes rivers (basically two orders of magnitude of difference), we expect the inflow to reach a significant extent off the river mouth (this is supported by observations; Fig. 1). As such, the fate of the inflow in its far field is also evaluated by considering the theory of Nof and Pichevin (2001) and adapting the quantitative results of Nof et al. (2002b) as their study framework is close to ours.

\section{a. General background}

Observations of river inflows into the ocean commonly reveal two types of structures (Chao 1988a; Kourafalou et al. 1996; Yankovsky and Chapman 1997): an anticyclonic circulation at the river mouth and a coastal current that propagates in the direction of coastal Kelvin waves. The anticyclonic circulation is induced by the input of river water that perturbs the vorticity balance. To help describe this, we consider a shallow layer of rotating fluid of a mean depth $H$, bounded by a flat, rigid surface at either the top or bottom and on the other side by a fluid of different density, forming an interface that deviates from the mean state by $\eta$ (positive if increasing the layer depth). 
TABLE 1. Observed and computed parameters of the Congo River. They are also used in the model in the REF experiment. List based on the Garvine (1999) study.

\begin{tabular}{|c|c|c|}
\hline Parameter & Name & Value \\
\hline$f$ & Coriolis frequency & $-1.52 \times 10^{-5} \mathrm{~s}^{-1}$ \\
\hline$L$ & River width & $27 \mathrm{~km}$ \\
\hline$h_{0}$ & River mouth depth & $30 \mathrm{~m}$ \\
\hline$h_{1}$ & Inlet depth & $10 \mathrm{~m}$ \\
\hline$S_{a}-S_{i}$ & Salinity difference & 15 \\
\hline$v_{i}$ & Inlet velocity & $0.148 \mathrm{~m} \mathrm{~s}^{-1}$ \\
\hline$T_{i}$ & Rate of flow & $40000 \mathrm{~m}^{3} \mathrm{~s}^{-1}$ \\
\hline$A$ & Tidal height amplitude & $0 \mathrm{~m}(1.1 \mathrm{~m}$ observed $)$ \\
\hline$g^{\prime}$ & Reduced gravity & $0.113 \mathrm{~m} \mathrm{~s}^{-2}$ \\
\hline$c_{i}$ & Internal wave speed & $1.063 \mathrm{~m} \mathrm{~s}^{-1}$ \\
\hline$r_{i}$ & $\begin{array}{c}\text { Rossby radius of } \\
\text { deformation }\end{array}$ & $70.0 \mathrm{~km}$ \\
\hline$\alpha$ & Shelf bottom slope & 0 \\
\hline
\end{tabular}

We cross differentiate the linear, shallow water momentum equations, which leads to

$$
\frac{\partial}{\partial t}\left(\zeta-\frac{f \eta}{H}\right)=-\frac{f Q}{H},
$$

where $f$ and $\zeta$ are, respectively, the planetary and relative vorticity; $\eta$ is the interface displacement; and $Q$ is the rate of flow that enters the conservation equation (positive for a source and negative for a sink). Considering that the layer depth is nearly constant and neglecting variations of the interface, we can deduce that a riverine source will induce a negative relative vorticity at a river mouth. In the case of the Congo River, whose mouth is at $6^{\circ} \mathrm{S}$, observations reveal an anticlockwise circulation with a disk shape and a coastal current propagating to the south, leaving the coast to its left, as expected in the Southern Hemisphere (D13, their Fig. 10.1). We will verify this in idealized numerical simulations as described later.

Beyond this theory, model-based works on the river inflows initiated in the 1970s (Garvine 1974; Kao et al. 1977, 1978) pointed out the dependency of the plume on numerous physical and numerical parameters such as the estuarine slope or the estuary width, influencing its shape, size, and stability. Many studies build up a plume classification based on these parameters, according to various criteria such as the relative offshore extension of the bulge compared to the coastal current (Chao 1988a) or the meanders and instabilities developed by the coastal current (Schiller and Kourafalou 2010). Garvine (1999) appears to be the first to provide the quasi-exhaustive list of physical parameters that influence the plume shape.

\section{b. The Congo River parameters}

Table 1 presents the real geometrical and physical parameters of the Congo River used to set up the reference

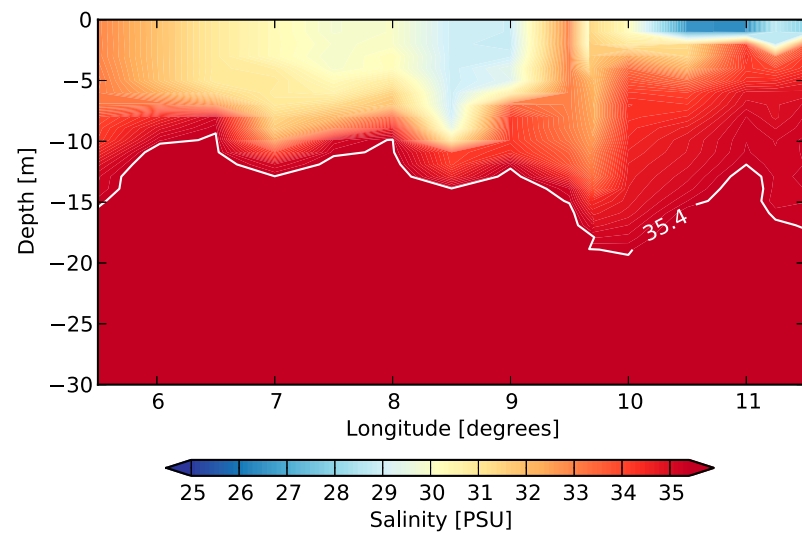

FIG. 2. Vertical salinity section (BIOZAIRE data, stations 22-38), along the path drawn in Fig. 1a. The white line is isohaline 35.4 psu, which can be approximated as the limit of the desalinated waters, as the max of salinity in the region is about $35.5 \mathrm{psu}$.

experiment (REF) described later. Here, we comment on how we choose these parameters. The Coriolis parameter is calculated at the river mouth $\left(6^{\circ} \mathrm{S}\right)$. The width and depth of the estuary are approximated as mean values out of the canyon area because of their spatial high variability. Based on the observation of Eisma et al. (1978) and Vangriesheim et al. (2009), we estimate the depth $h_{1}$ of the freshwater surface layer (Fig. 2) and the salinity difference $\Delta S$ between the inflow and the ambient shelf water. Depending on the location and naturally decreasing when going downstream, $\Delta S$ is about $15 \mathrm{psu}$ [in a range that is consistent with the usual values for coastal plumes, as Kao et al. (1977) notice a salinity difference of $16 \mathrm{psu}$, for instance]. The inlet velocity $v_{i}$ is computed as the ratio of the freshwater flux to the section of the estuary, as $L h_{1} v_{i}$ is the rate of flow. To compute a reduced gravity $g^{\prime}$ representative of the plume, we use a linear model of density calculation varying with the salinity: $\Delta \rho=r_{\beta} \times \Delta S$, with $r_{\beta}=0.824 \mathrm{~kg} \mathrm{~m}^{-3} \mathrm{psu}^{-1}$. In fact, in its first approximation, the temperature would not influence density much, as the thermocline is not very marked and lies under a sharp halocline due to the freshwater discharge (Jourdin et al. 2006; Vangriesheim et al. 2009). The propagation speed of the gravity internal waves in a two-layer model is formally $c_{i}=\left[g^{\prime} h_{1} h_{2} /\left(h_{1}+\right.\right.$ $\left.\left.h_{2}\right)\right]^{1 / 2}$, which is frequently approximated to $\left(g^{\prime} h_{1}\right)^{1 / 2}$ if the upper layer is much thinner than the bottom layer, as is the case for the Congo plume (see Fig. 2). The shelf bottom slope $\alpha$ is neglected at first. Later on we carry out sensitivity experiments to determine the impact of the slope on the dynamics.

\section{c. Nondimensionalized parameters}

Defining seven geometrical and physical parameters ( $f, L, h_{1}, S_{a}-S_{i}, T_{i}$, and $A$; see Table 1 ) holding two 
TABLE 2. Nondimensional parameters computed from Table 1. List based on the Garvine (1999) study.

\begin{tabular}{cll}
\hline \hline & \multicolumn{1}{c}{ Name } & \multicolumn{1}{c}{ Value } \\
\hline $\begin{array}{c}\text { Nondimensional parameters } \\
\tau=\frac{2 T_{i} f}{g^{\prime} h_{1}^{2}}\end{array}$ & $\begin{array}{c}\text { Scaled inlet } \\
\text { transport }\end{array}$ & 0.108 \\
$K_{i}=\frac{L}{r_{i}}$ & Kelvin number & 0.38 \\
$\alpha$ & Shelf bottom slope & 0 \\
$\epsilon=\frac{A}{h_{1}}$ & Scaled tidal & $0(0.11$ \\
$\frac{L}{h_{1}}$ & amplitude & observed $)$ \\
Alternative parameters & Aspect ratio & 2700 \\
$F_{i}=\frac{v_{i}}{c_{i}}=\frac{\tau}{2 K_{i}}$ & Froude number & 0.139 \\
$\operatorname{Ro}_{i}=\frac{v_{i}}{f L}=\frac{\tau}{2 K_{i}^{2}}$ & Rossby number & 0.289 \\
\hline
\end{tabular}

independent dimensions (time and length), one can determine five nondimensional, independent parameters $\left(\tau, K_{i}, \alpha, \epsilon\right.$, and $L / h_{1}$; see Table 2$)$ driving the dynamics. We can interpret them separately, deducing some expected theoretical characteristics of the Congo plume (the role of the shelf slope $\alpha$ is discussed later):

(i) The scaled inlet transport $\tau$ satisfies $\tau \ll 1$. This implies that the river transport is far less important than the geostrophic flow induced by the gravity current. The river dynamics can therefore be neglected in the setup of the intrinsic buoyancy-driven dynamics of the plume. Independently, this parameter is also used by Yankovsky and Chapman (1997), who associate $\tau \ll 1$ with surface plumes, leading to consistency with what we found.

(ii) The inlet Kelvin number verifies $K_{i}<1$, which shows that Earth's rotation does not play an important role in the dynamics. This is due to the nearequatorial position of the river mouth and implies that the coastal current does not transport much freshwater in comparison with the lens.

(iii) The scaled tidal amplitude is very weak as suggested by the parameter $\epsilon \ll 1$ (from Eisma et al. 1978), which means that the tidal effect has a negligible importance over the near-field plume dynamics. As such, we do not take the tide into account in our experiments.

(iv) The aspect ratio $L / h_{1} \gg 1$ shows that the outflow is mainly horizontal and that we can use the hydrostatic approximation in further simulations [this aspect ratio has an importance for laboratory tank experiments (Sutherland and Cenedese 2009)].

The first two nondimensional parameters $\tau$ and $K_{i}$ are both linked with other parameters: the inlet Froude number $F_{i}=v_{i} / c_{i}=\tau /\left(2 K_{i}\right)$ and the inlet Rossby number $\mathrm{Ro}_{i}=v_{i} /(f L)=\tau /\left(2 K_{i}^{2}\right)$. The inlet Froude number $F_{i}<1$ can be interpreted as a prevailing input of potential energy rather than kinetic energy (Garvine 1999). The inlet Rossby number $\mathrm{Ro}_{i}=O(1)$ indicates that the flow is not completely geostrophic at the river mouth and presents nonlinearities in the near-field plume development as we expect advection to play a role in the salt transport.

Even if the theoretical results of Yankovsky and Chapman (1997) place the Congo plume as surface trapped, D13 notice that the geomorphology of the estuary (partly represented through the shelf slope $\alpha$ ) plays an important role in the plume morphology. This is why we further dedicate sensitivity experiments to the influence of the bottom slope, taking into account previous idealized studies such as the ones of Kourafalou et al. (1996) and Chao (1988a) that reveal that the slope has a trapping effect on the bulge at the coast, slowing down its offshore extension.

In summary, the major theories of unforced plumes indicate that the Congo River parameters are in a range that induces a surface-trapped plume without any influence of the bottom slope and a large-scale, horizontal, anticlockwise geostrophic circulation with an offshore spreading bulge largely dominating a small coastal current going southward. Furthermore, the dynamics should be dominated by the gravity current rather than by the transport generated by the river inflow. Concerning the tidal impact, observations show that it is negligible (Eisma et al. 1978).

\section{d. Near-field plume morphology}

Here, we concentrate on the Yankovsky and Chapman (1997) study that appeared to be the most relevant for the near-equatorial case to describe the near-field plume morphology. Their theory classifies the plume in two distinct categories. On the one hand, the plume can be surface trapped, which means that the freshwater thin surface layer does not have any interaction with the bottom and the anticyclonic bulge extends offshore with a disk shape. On the other hand, it can be bottom influenced, which means that in this parameter range, the plume feels the bottom friction and its offshore extent is compromised by its vertical and coastal spread. This theory is based on simple hypotheses such as the cyclogeostrophic equilibrium on an $f$ plane in the bulge that involves a balance between the pressure force, the Coriolis force, and the centrifugal force:

$$
-v^{2} / r-f v=-g^{\prime} \frac{\partial h_{1}}{\partial r}
$$

where $v$ is the azimuthal velocity, $r$ is the bulge radius, $f$ is the planetary vorticity, and $g^{\prime}$ is the reduced gravity 
between the upper thin layer of freshwater of depth $h_{1}$ and the bottom layer of ambient shelf water (values are found in Table 1). Considering a constant vertical shear of the horizontal velocities, Yankovsky and Chapman (1997) calculate the depth at which the plume should be trapped:

$$
h_{b}=\left(2 L v_{i} h_{1} f / g^{\prime}\right)^{1 / 2}
$$

Within the real Congo River parameters that are also used in the model (Table 1), we have $h_{b}=3 \mathrm{~m}<h_{1}$. The predicted equilibrium depth for the bottom-influenced plume is shallower than the real depth of the buoyant inflow so the plume is surface trapped. In Eq. (3), the Coriolis frequency acts in favor of trapping by the surface for a near-equatorial plume. This feature is observed in the BIOZAIRE cruises (see salinity section of Fig. 2) carried out by L'Institut Français de Recherche pour l'Exploitation de la Mer (IFREMER) between 2000 and 2005 (Vangriesheim et al. 2009) and OPTICCONGO carried out by the Service Hydrographique et Océanographique de la Marine (SHOM) in March 2005 (Jourdin et al. 2006), where the Congo plume is surface trapped with no evidence of coastal current (it would have been necessarily noticeable if the plume was bottom influenced). The shape of the surface bulge is also observed to spread like a lens in the satellite observations of CDM absorption length of GlobColour data (Maritorena et al. 2010) and sea surface salinity of SMOS data (Boutin et al. 2012) (see Fig. 1). The realistic simulations of D13 confirm these aspects of the observations. However, the strongest hypothesis of Yankovsky and Chapman (1997) is that the flow is in dynamical balance with no growth of the bulge radius at the equilibrium state. This implicitly hides the fact that a balance is reached between advection and diffusion of buoyancy after a certain period (Garvine 1999). Dynamics of inviscid outflow leads to different results.

\section{e. High rate of flow plume dynamics at long time scales}

Studies of Pichevin and Nof (1997), Nof and Pichevin (2001), Nof et al. (2002a,b), and Nof (2005) focus on inviscid outflows, inflows, and throughflows spreading in a $\beta$-plane ocean through straits or archipelagos. The first paper of this list highlights the fact that the outflowing bulge cannot be in momentum balance (under the assumption of no momentum viscosity nor diffusivity) as nothing can counterbalance the force exerted by the alongshore current. Consequently, the plume is shedding eddies that are moving contrary or at a right angle to the coastal current, depending on the coast orientation. These theory- and attendant-derived cases (depending on the geometry of the configuration) give general features of some real outflows (Indonesian Throughflow, Red Sea outflow, and Loop Current, for instance). Although this framework is useful for studying outflows with high rates of flow [greater than 0.1 Sverdrups (Sv; $\left.1 \mathrm{~Sv} \equiv 10^{6} \mathrm{~m}^{3} \mathrm{~s}^{-1}\right)$, as the ones cited], it has never been referred to when dealing with river inflows, as their rates of flow are generally much lower (order of magnitude of $0.001 \mathrm{~Sv}$ ). In fact, the bulge has to reach a certain size defined by the theory before being sheared by the planetary vorticity gradient and relaxing eddies that drift westward due to $\beta$. Basically, if the rate of flow is not important enough, diffusion processes of buoyancy due to the wind or tidal mixing effects impede a sufficient development of the lens.

The Congo River presents a mean outflow of $0.04 \mathrm{~Sv}$ and is seemingly not topographically controlled (Yankovsky and Chapman 1997), which is a necessary assumption to use this theory, so we could expect its associated bulge in a nonforced case (without wind and tide) to grow sufficiently to shed eddies. To describe the expected behavior, we use the framework of Nof et al. (2002b) applied to the Indonesian Throughflow that has the same configuration as the African west coast at the Congo River latitude with its meridional coastline oriented westward.

The detachment condition of the eddy is that its westward drift just exceeds its growth rate (Nof et al. 2002b), and then the vortex detaches from the coast and migrates westward. Equating the growth rate of the eddy $d R / d t$, where $R$ is the eddy radius, with the drifting velocity of nonlinear eddies (2/3) $\beta R d^{2}$ (Nof 1981) gives the final eddy radius. Adding an assumption on the vorticity profile of the growing lens, Nof et al. (2002b) find an analytical solution for the eddy radius and their frequency of ejection. For a linear orbital speed of $v_{\theta}=(-\alpha / 2) f R$ (meaning that the relative vorticity is $\zeta=-\alpha f, \alpha$ being a nonlinearity parameter), the final radius of the eddy at detachment is

$$
R_{f}=\frac{2 \sqrt{2}}{[(2-\alpha) \alpha]^{1 / 2}}\left[\frac{3 \alpha^{1 / 2}(2-\alpha)^{3 / 2}}{8 \sqrt{2} \pi} \frac{g^{\prime} T_{i}}{\beta f^{2}}\right]^{1 / 5}
$$

and the period of ejection is

$$
T=\frac{48(1-\alpha / 2)}{(2-\alpha) \alpha}\left(\beta R_{f}\right)^{-1} .
$$

Figure 3 shows that the radius and period of ejection of eddies are very sensitive to the vorticity profile. The smallest period is reached for highly nonlinear eddies $(\alpha=1)$ and is greater than 100 days at the Congo latitude (bold lines). The "Baseline" run performed by D13 


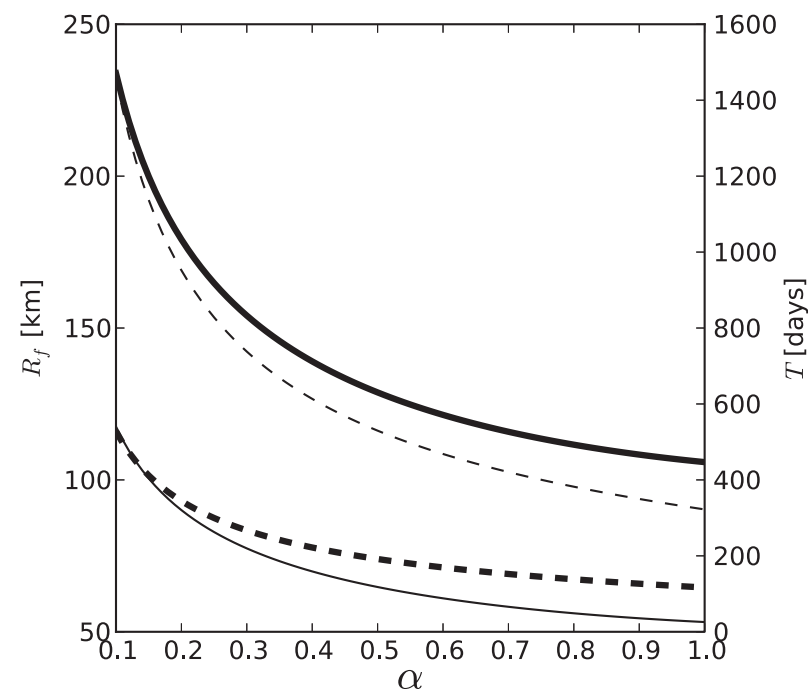

FIG. 3. Max radius $R_{f}$ (plain) and period of ejection $T$ (dashed) of the eddies at the Congo lat (bold) and at $46^{\circ} \mathrm{S}$ (thin), depending on the nonlinearity parameter $\alpha$. See Eqs. (4) and (5).

(i.e., with no forcing but a realistic coastline and bathymetry) was only run for 40 days to avoid spurious interactions between currents in the plume and boundaries of the domain, so they were not able to observe $\beta$ pulling of nonlinear structures offshore.

In conclusion, this theory applied to our case study reveals that the high rate of flow of the Congo River combined with its equatorial position imposing small $f$ (thus large radius of deformation) and high $\beta$ acts in favor of an important westward $\beta$ pulling of nonlinear vortical structures according to Eq. (5) derived from Nof et al. (2002b).

\section{Model description}

To verify our theoretical results concerning the Congo plume classification, we carry out numerical experiments. We use idealized configurations, starting from a simplified unforced problem with different assumptions on the Coriolis parameter, and then evaluate the role of wind and topography through sensitivity experiments. Here, we describe the reference experiment (hereafter REF). In contrary to the Baseline unforced simulation of D13 performed for 40 days to see the nearfield extent, we ran the simulations for 1500 days to see the fate of the plume at long time scales, testing the validity of the Nof et al. (2002b) theory.

We use the Regional Ocean Modeling System [ROMS; see Shchepetkin and McWilliams (2005) for a complete description] in its version 3.0. ROMS solves the primitive equations on an orthogonal curvilinear coordinate system. The latter is terrain following to better represent the effect of topography on the fluid. The advection scheme is third-order upstream biased, has low numerical dissipation, and is assessed to be strong enough not to add physical explicit eddy viscosity nor tracer diffusivity in the interior of the domain. The diffusive part of the advection scheme is rotated along the iso-geopotential surfaces to avoid spurious diapycnal mixing as explained in Marchesiello et al. (2009). Subgrid-scale vertical mixing processes are parameterized using the $K$-profile planetary (KPP) boundary formulation (Large et al. 1994).

Our configuration is based on a $1 / 12^{\circ}$ grid with idealized meridional coastline and a waterway at the Congo River mouth latitude at $6^{\circ} \mathrm{S}$. Bathymetry is constant in the basin $(1000 \mathrm{~m})$ and the waterway $(30 \mathrm{~m})$. Between the basin and the waterway, topography follows a slope of approximately $1 \%$. The grid has 40 vertical levels with refinement only at the surface using stretching parameters $\theta_{s}=6.5$ and $\theta_{b}=0$ (Haidvogel and Beckmann 1999) with geometrical transformation parameter Vtransform $=2$. The minimum depth at which stretching occurs is defined in the parameter $h_{c}=$ $300 \mathrm{~m}$, and the minimum depth represented is $15 \mathrm{~m}$. The western, southern, and northern boundaries are open with viscosity coefficient of $300 \mathrm{~m} \mathrm{~s}^{-2}$ on a sponge layer of width $100 \mathrm{~km}$. The river runoff is prescribed at the end of the waterway, and steady stratification on the column is effective on the waterway. Temperature is taken uniform on the domain as well as salinity of $35.5 \mathrm{psu}$, which is the maximum reached in the subsurface in this region according to the Levitus climatology (Levitus 1982). Temperature and salinity are taken as constant to isolate the influence of the river inflow on the buoyancy in the basin.

The topography used for the TOPO and WIND sensitivity experiments (deeply described later) is from the 2-Minute Gridded Global Relief Data (ETOPO2) (Smith and Sandwell 1997). It has been smoothed under the constraint $\Delta h / 2 h<0.2$. The wind stress of the WIND experiment is an annual mean computed from the Scatterometer Climatology of Ocean Winds (SCOW) monthly climatological dataset (Risien and Chelton 2008) computed for 122 months (September 1999-October 2009) of Quick Scatterometer (QuikSCAT) data (dataset is available at a $1 / 4^{\circ}$ resolution at http://cioss.coas. oregonstate.edu/scow/) (Fig. 4).

\section{Buoyancy-driven dynamics of the REF experiment}

During the first 150 days of the simulation, we observe the growth of the surface lens with its anticyclonic circulation (Fig. 5) and the spreading of a coastal current in the direction of the coastal Kelvin wave propagation, in 


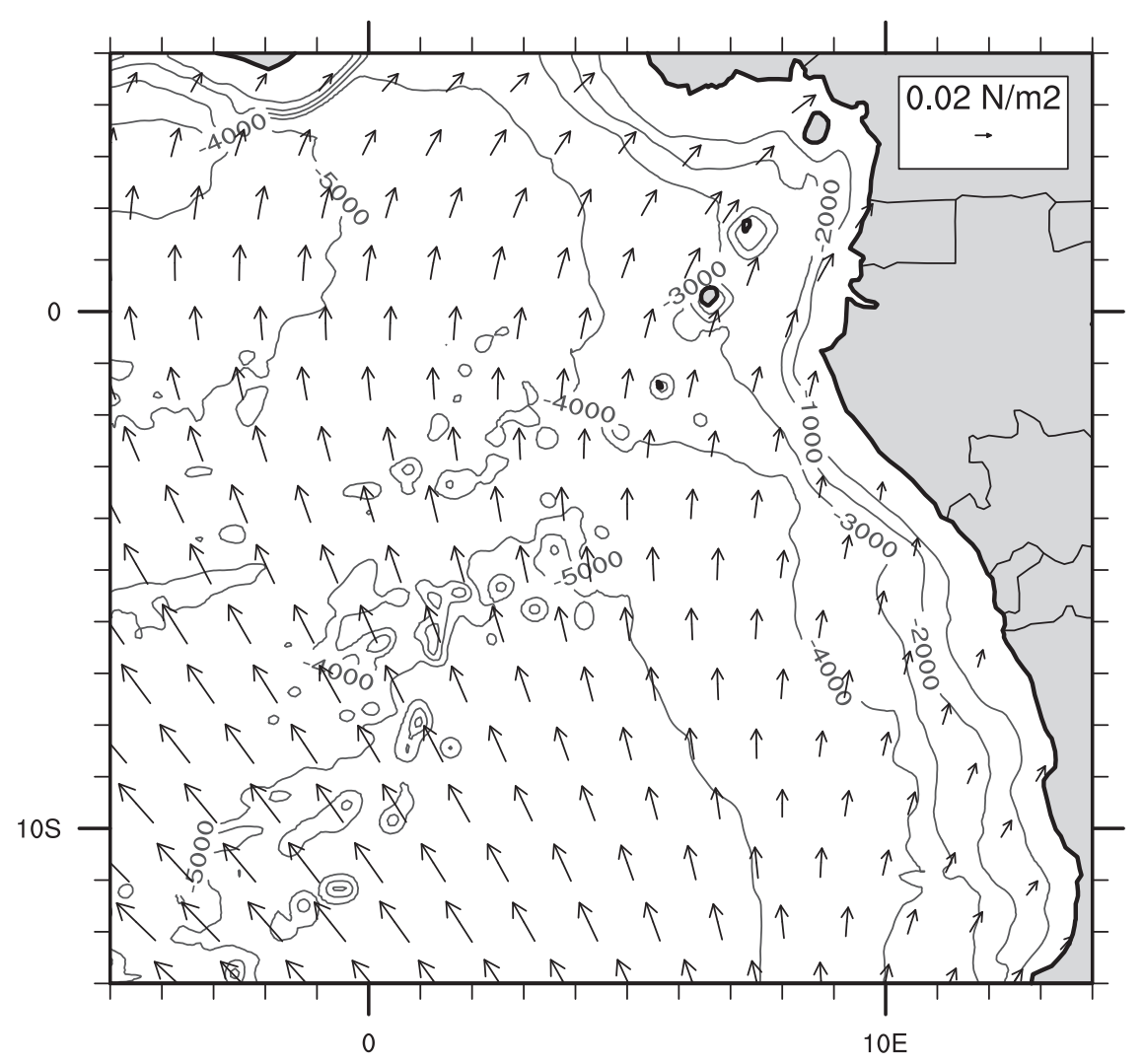

FIG. 4. Bathymetry and wind stress fields used in TOPO and WIND experiments (see text for details). Topography contour interval is $1000 \mathrm{~m}$. Wind stress is an annual mean (SCOW climatology).

coherence with the theory. Compared to the low Kelvin number experiments of Garvine (1999) (cf. his Figs. 7 and 8 with our Fig. 5a), the plume develops in a predicted way, with a huge anticyclonic bulge (see map of surface relative vorticity in Fig. 6a at 100 days of simulation) containing most of the desalinated waters and a narrow coastal current. This is due to the weak impact of the Coriolis force on the dynamics near the equator, as deduced from the low Kelvin number $K_{i}$. The nondimensionalized, surface relative vorticity $\zeta /|f|$ scales as the Rossby number and is a good indicator of the degree of geostrophy of the flow. Figure 6a displays relatively high vorticity patterns $(\zeta /|f|>0.7)$ that indicate that the flow departs from geostrophy just at the waterway mouth. The Rossby number found in the theory (Table 2) reveals an important part of the advection in the plume dynamics that is verified in simulations.

Figure 7a presents a vertical section of salinity in the axis of the waterway at 500 days of simulation for the REF experiment. We verify that the layer of low-salinity water is contained at the surface and does not reach the bottom in the waterway, as anticipated by the theory. The plume classification as surface trapped is validated by both the section and the morphology of the surface bulge [see schematics of Figs. 1 and 2 of the Yankovsky and Chapman (1997) study]. This is seemingly a robust result of equatorial plumes as we show that a weak Coriolis frequency acts in surface trapping the bulge [Eq. (3)]. The depth of the surface layer is between $10 \mathrm{~m}$ at the river mouth and $40 \mathrm{~m}$ in the core of the plume according to the white line representative of isohaline $35.4 \mathrm{psu}$ (background salinity is $35.5 \mathrm{psu}$ ). It is difficult to determine its depth precisely because the bottom limit of the plume is not as marked as in the observations. Nonetheless, we notice that this depth range includes the one of the BIOZAIRE section (Fig. 2), which is around $20 \mathrm{~m}$.

As demonstrated by Pichevin and Nof (1997) and Nof and Pichevin (2001), and noticed by Fong and Geyer (2002), the lens cannot reach a stationary state and its offshore-oriented growth is the result of a balance between three alongshore forces: the "jet" force (Nof et al. 2002b) resulting from the downstream current, the integrated Coriolis force resulting from the offshore displacement of the eddy center, and the $\beta$-induced force pulling it equatorward. The bulge reaches a critical size 

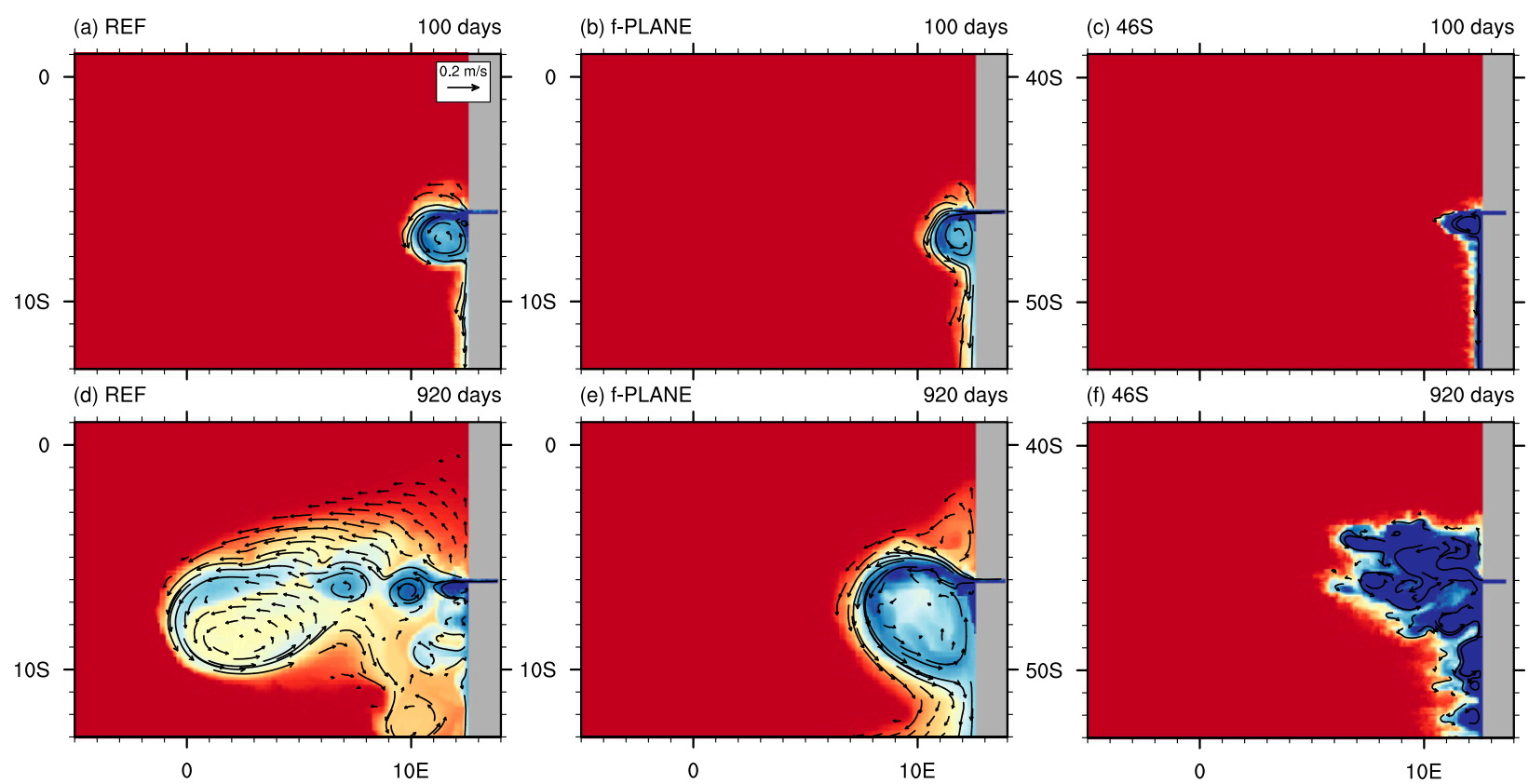

Sea Surface Salinity [PSU]

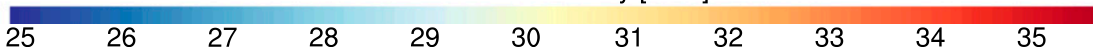

FIG. 5. SSS and surface velocity field at 100 and 920 days of simulation for the REF experiment with no assumption on the (a),(d) Coriolis frequency, for the (b),(e) $f$-plane experiment, and the (c),(f) midlatitude experiment $46^{\circ} \mathrm{S}$.

as discussed in the previous section, and mesoscale anticyclonic eddies are ejected, transporting low-salinity waters offshore (Fig. 5d). Figure 8 is a time-latitude diagram of sea surface height (SSH) at longitude $10^{\circ} \mathrm{E}$. This representation allows one to visualize separately the eddies' shed, thus assessing their averaged size and period of shedding. The size of eddies is about $200 \mathrm{~km}$ (we exclude the first structure displaying high SSH that is formed by aggregation of eddies), and their averaged period of ejection is 42 days. High values of $\zeta /|f|$ in vortex cores (Fig. 6b) are representative of nonlinear eddies, and according to Fig. 3, we should observe shedding periods of about 110 days. However, Nof et al. (2002b) find a similar discrepancy of a factor of 2 between their theoretical and experimental periods of ejection. Nevertheless, the size of eddies is in good agreement with the theory as their radius is estimated to $110 \mathrm{~km}$ (Fig. 3). (a) REF

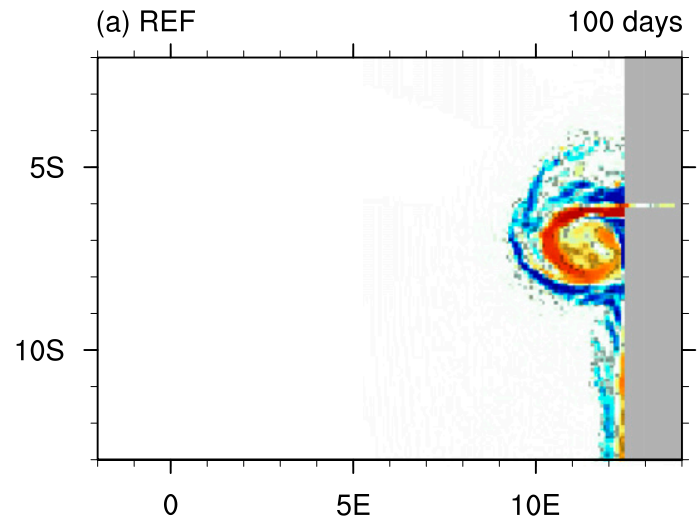

(b) REF

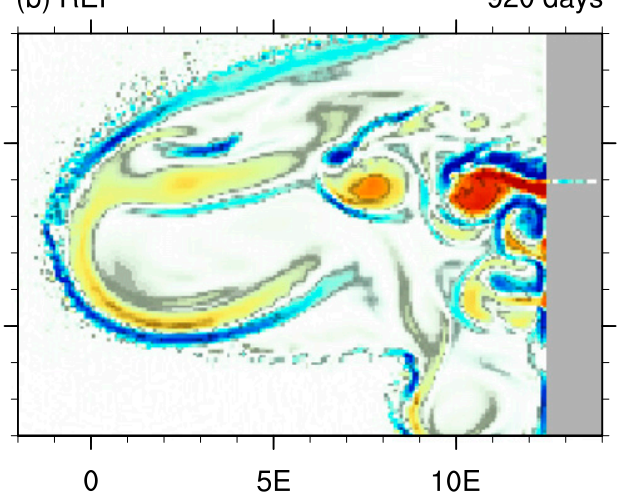

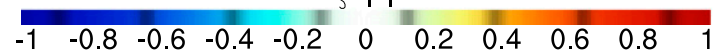

FIG. 6. Surface relative vorticity $\zeta$ nondimensionalized by the Coriolis frequency $|f|$ for the REF experiment at (a) 100 and (b) 920 days of simulation. 


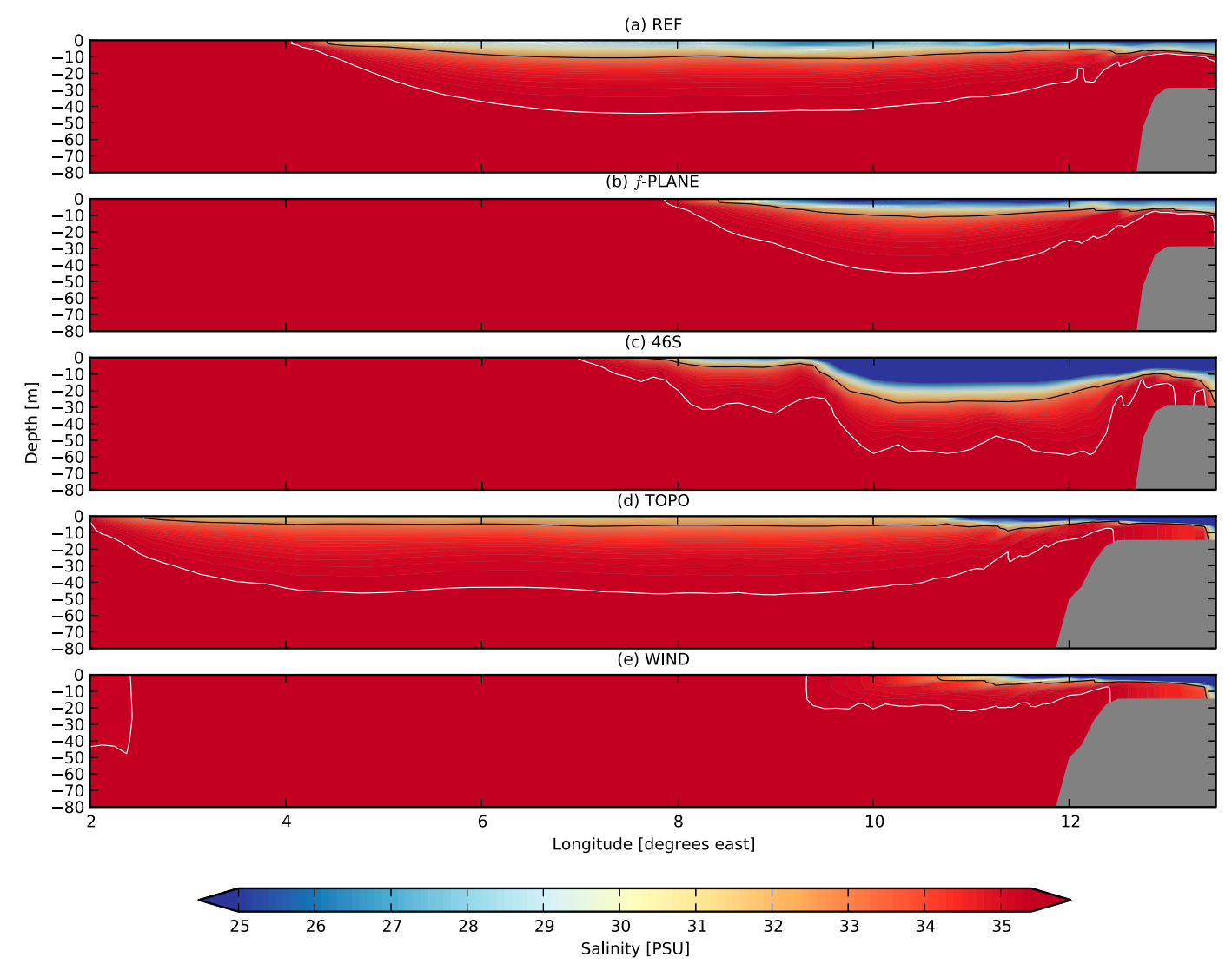

FIG. 7. Vertical zonal sections in the axis of the middle of the waterway at 500 days of simulation. (a) REF experiment, (b) $f$ PLANE, (c) $46^{\circ} \mathrm{S}$, (d) TOPO, and (e) WIND. The white (black) line is the isohaline $35.4 \mathrm{psu}$ (33 psu), which determines the limit of the plume, as the salinity in the basin is taken constant of $35.5 \mathrm{psu}$.

As vortical structures shed are anticyclonic, they are expected to move equatorward (Sutyrin and Flierl 1994; Morrow et al. 2004). Surprisingly, this behavior does not occur and seems to be overwhelmed by another process very active in our experiments, that is, the interaction between like-sign vortices (Carton 2001). Indeed, the distance separating the eddies of the REF simulation (identified in surface relative vorticity; Fig. 6b) is less than the critical merger distance that is approximately 3.3 times the vortex radius (Carton 2001), and this is why merging occurs. This phenomenon is often preceded by a rotation of the eddy centers around each other in a direction depending on their polarity. Two anticyclonic vortices move around each other in an anticyclonic

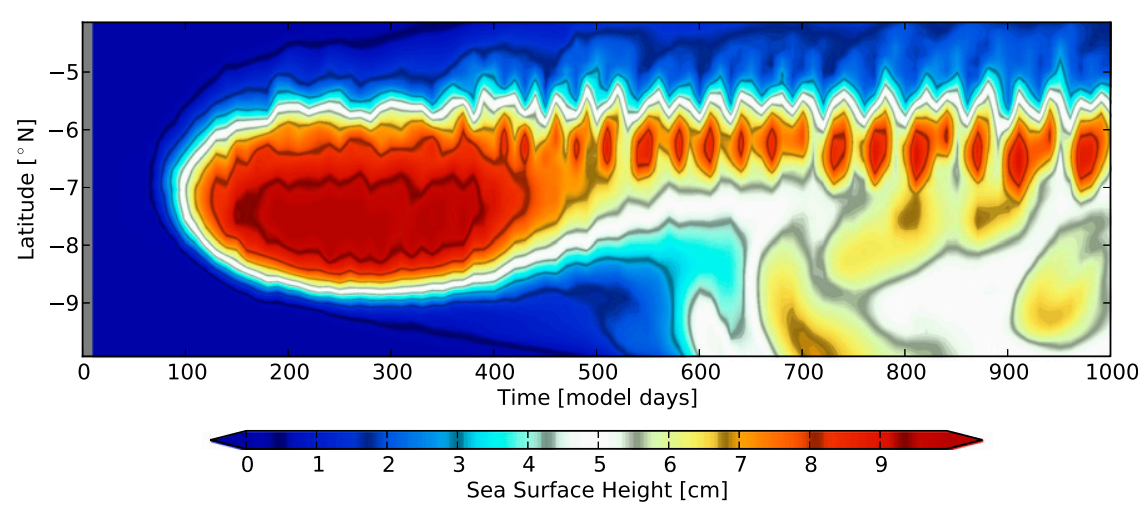

FIG. 8. Time-lat diagram of the SSH for the REF experiment at $10^{\circ} \mathrm{E}$. 
motion, and this is what we observe before merging the structures. The closeness of the eddies is therefore a prevailing condition that makes them interact strongly and impedes their westward drift to be deflected equatorward. The large-scale bulge (Fig. 5) of low-salinity water is the result of merging smaller anticyclones. The downstream coastal current also becomes unstable and develops meandering patterns and recirculation cells close to the coast, but we do not focus on these instabilities.

The REF experiment verifies the main characteristics of the plume developed in the theoretical part, in its near field as well as in its fate at long time scales. In terms of near-field plume morphology, theory and experiment confirm that it is surface trapped and that the large anticyclonic circulation overwhelms the weak coastal current. The Congo River high rate of flow associated with its near-equatorial position seem to be a sufficient condition for the shedding of eddies transporting low-salinity waters far offshore of the river mouth, as commonly observed in the real case (Fig. 1). To test the robustness of this explanation for the large offshore extent of the plume, we carry out sensitivity experiments on Earth's rotation effect and on wind and topographic forcing on the plume.

\section{Sensitivity of the plume}

We use two sensitivity experiments to evaluate the role of the near-equatorial position on the dynamics. The $46^{\circ} \mathrm{S}$ experiment is derived from the REF experiment by shifting every grid point by $40^{\circ}$ poleward. As a consequence, the river mouth that is normally situated at $6^{\circ} \mathrm{S}$ is now at $46^{\circ} \mathrm{S}$. The $f$-plane experiment differs from the REF experiment by the $f$-plane approximation made on the domain. The Coriolis frequency is taken as constant everywhere at the value it has at the river mouth (Table 1).

According to D13 findings, the geomorphology of the Congo River plume environment plays an important role in its development in the upstream direction. In addition, many studies [see Kourafalou et al. (1996) and Chao (1988a), for instance] reveal that the estuarine slope and the continental shelf have an impact on midlatitude plumes, which is why we measure the sensitivity of the plume on a real bathymetry in the TOPO experiment.

The Congo River enters the ocean at a latitude where steady trade winds blow during the majority of the year and develop coastal upwellings (Verstraete 1992). To assess the effect of the wind on the plume, we use a real forcing by wind stress in the WIND simulation. Winds are parallel to the coast and upwelling favorable in the Congo mouth vicinity.

\section{a. Effect of Earth rotation}

The $46^{\circ} \mathrm{S}$ experiment confirms that some of the distinguishing features of the near-equatorial plume cannot be reproduced at midlatitudes. In Figs. 5c and 5f, we see that the extent of the bulge is far less important than in the REF experiment, and the coastal current is much better developed, containing more low-salinity water, in coherence with the high Kelvin number experiment of Garvine (1999) (cf. his Fig. 7 with the current Fig. 5f). As the Coriolis force is about 7 times stronger in midlatitudes (at $46^{\circ} \mathrm{S} ; f=1.05 \times 10^{-4} \mathrm{~s}^{-1}$ ), the flow is more tilted to the left directly at the river mouth, and the anticyclonic circulation cannot spin up as smoothly as it does in the near-equatorial case. We also notice in Fig. 7c that the depth of the plume is greater than in the REF case, as suggested by the theory of Yankovsky and Chapman (1997) that implies a larger influence of the bottom at higher latitudes. The freshwater layer in the waterway is also deeper because the Coriolis force creates a meridional slope of the low-salinity layer depth, thinning it northerly and deepening it southerly.

At midlatitudes, the minimal period required to shed eddies is more than 300 days (Fig. 3, thin lines) for the highest nonlinear eddies $(\alpha=1)$. This time scale is much higher than the characteristic time of baroclinic and frontal instabilities developing in the bulge. For instance, Fong and Geyer (2002) and Kourafalou et al. (1996) found the order of magnitude of destabilization times of about 10 days. Small anticyclonic eddies sometimes detach from the lens, but they are drifting westward too slowly and merge with other anticyclonic structures of the plume. In fact, with an equivalent stratification (that is the case of our simulations), their drifting velocity $\propto \beta\left(g^{\prime} h_{1} / f^{2}\right)$ is reduced by nearly two orders of magnitude. ${ }^{1}$ As a consequence, even with an important rate of flow, $\beta$ pulling of nonlinear structures is not an active mechanism for transporting low-salinity waters off the river mouth at midlatitudes, and this may be a reason why, to the authors' knowledge, no study dedicated to the midlatitudes' river plume describes the ejection of eddies.

On the $f$-plane experiment, we confirm that the nearfield plume has the same shape as in the REF simulation (Figs. 5a,b). The growth of the bulge does not show any difference with the REF until about 150 days when it reaches a sufficient diameter that makes it feel the gradient of $f$. On the sphere, the lens detaches from the coast due to the $\beta$ effect, whereas on the $f$ plane, its growth is unlimited as an outflow can never be steady

\footnotetext{
${ }^{1}$ Divided by $1.4 \times 7^{2}$ as $f_{46^{\circ} \mathrm{S}} \approx 7 \times f_{\mathrm{REF}}$ and $\beta_{46^{\circ} \mathrm{S}} \approx \beta_{\mathrm{REF}} / 1.4$.
} 

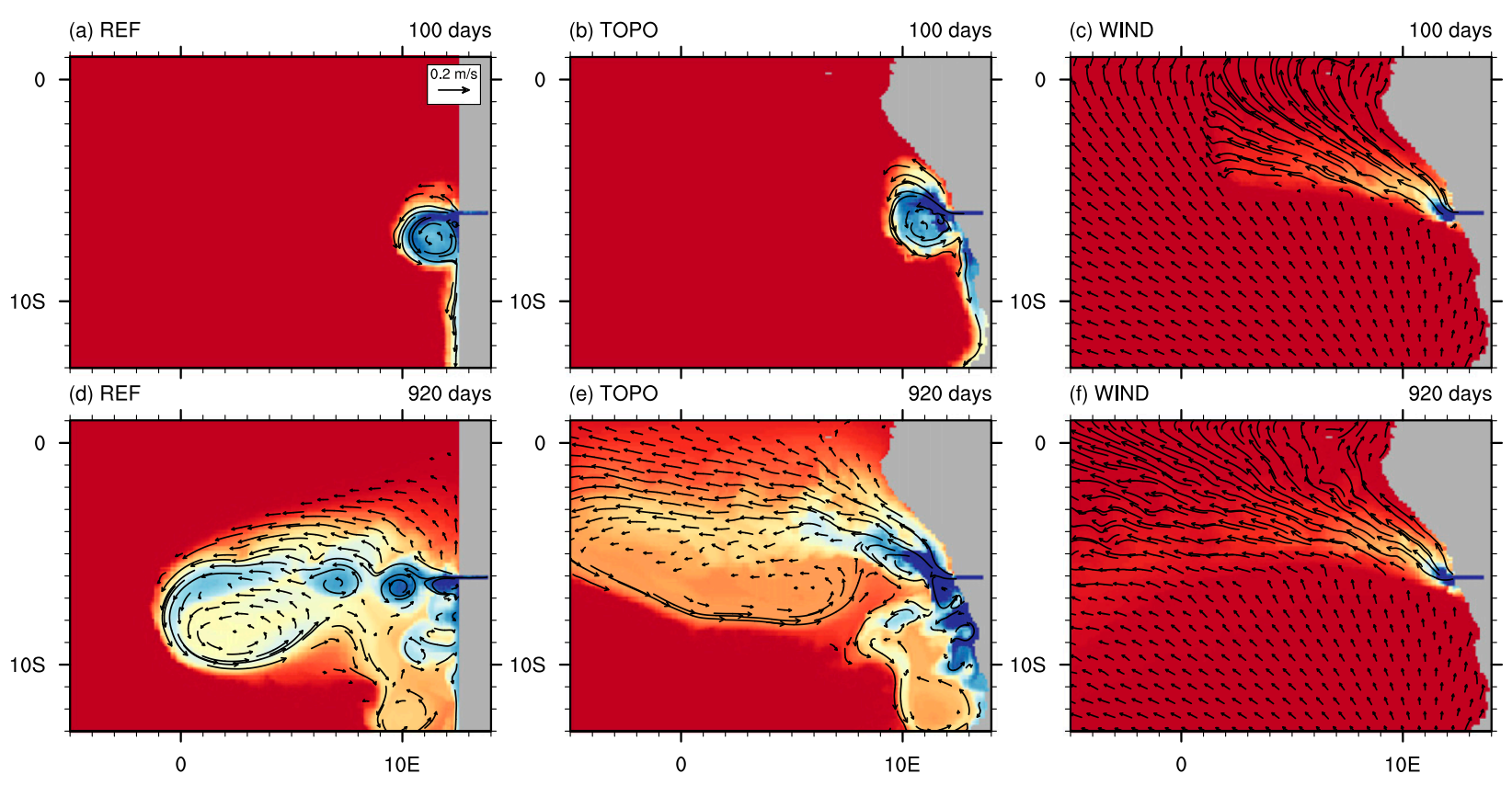

Sea Surface Salinity [PSU]

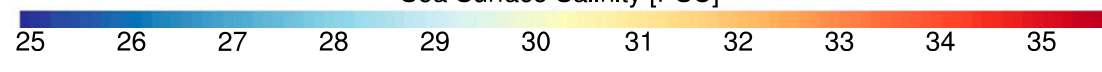

FIG. 9. SSS and surface velocity field at 80 and 300 days of simulation for the (a),(d) REF experiment, for the (b),(e) TOPO experiment, and the (c),(f) WIND experiment.

(Nof et al. 2002b). The impact of $\beta$ on the transport of low-salinity waters is clearly seen on the sections of Fig. 7 where the offshore extent of the bulge nearly doubles between REF and $f$ plane.

Those experiments clearly underline the importance of the $\beta$ effect to reproduce the offshore drift of lowsalinity waters observed in satellite measurements (Fig. 1) and modeled in the realistic numerical simulations of D13. In fact, because of the huge rate of flow and the near-equatorial position of the river mouth, the meridional length scale of the plume is larger than in previously published experiments carried out at midlatitudes with weaker rates of flow. This allows the development of westward $\beta$ pulling of nonlinear structures.

\section{b. Impact of the geomorphology}

The estuarine and the shelf slopes tend to trap the plume at the coast and limit its offshore extension (Kourafalou et al. 1996; Chao 1988a). Shallow waters are also more inclined to be bottom influenced (Yankovsky and Chapman 1997). Nevertheless, these results apply mainly to midlatitude plumes, which are more likely to feel the influence of the topography and the bottom Ekman layer as reviewed before. This can be seen in the computation of $h_{b}$ [Eq. (3)] that varies as $f^{1 / 2}$, which means that the greater $f$, the more likely the plume to be bottom influenced. The TOPO experiment is set up to assess the impact of the real geomorphology and topography of the Congo River environment on its plume.

The scenario of the plume spreading is threefold. From the onset of the plume until about 130 days, its growth does not show any major difference with the REF experiment (Figs. 9a,b), developing an anticyclonic circulation and a downstream coastal current. The only small difference can be seen in the vertical structure of the plume whose isohaline $35.4 \mathrm{psu}$ intersects the bottom (Fig. 7; although the figure is at 500 days and stratification in the waterway does not vary after 40 days of simulation), which is a distinguishing feature of bottominfluenced plumes. This trapping is certainly due to the shallower estuarine bathymetry and the smoother shelf slope, divided by almost three compared to the REF configuration.

As such, from 130 to about 300 days, the plume develops an upstream, coastally trapped current (Chapman and Lentz 1994) that has been shown to be a robust feature of bottom-influenced plumes (Matano and Palma 2010). The excursion of this current reaches a critical latitude at which dynamics can be interpreted in terms of wave propagations in a more linear regime than the geostrophic turbulence of midlatitudes (Theiss 2004). 
This critical latitude has been noticed to be around $3^{\circ}$ in regional primitive equation simulations (Penven et al. 2005). An important part of low-salinity waters seem to be pulled by the upstream current forming a large tongue northwestward of the river mouth.

Onward, two mechanisms modulate the transport of low-salinity waters. Examining Fig. 10 (SSH Hovmöller diagram at $2^{\circ} \mathrm{S}$ ) leads to the distinction of two phenomena that seem to be trapped in the equatorial band. First, the propagation of the front of the tongue is noticeable by the most important $\mathrm{SSH}$ gradient that crosses the basin at a nearly constant speed of $3 \mathrm{~cm} \mathrm{~s}^{-1}$. This advective speed is associated with the movement induced by the baroclinic pressure of the constantly refilled upper layer (Nof et al. 2002b). Second, westward-propagating waves behind the front are generated near the coast and travel at a speed of about $12 \mathrm{~cm} \mathrm{~s}^{-1}$. These waves stop propagating at the front, which means that they need the plume-like stratification to exist (Nash and Moum 2005) and cannot be projected on classical equatorial wave modes that propagate on the background stratification of the model. Many crests of these waves can be observed in the signal and allows a dominating period of 32 days to be distinguished. Figure 11 can be compared to Fig. 8, as it shows the same eddy propagation field for the TOPO experiment at a latitude shifted by $1^{\circ}$ northward. This northward shift between both simulations is certainly due to the northward-oriented estuary that deflects the flow in this direction. The same eddies are observed as in the REF experiment, but the signal is a bit noisier and attenuated (note the different color scales). The detaching period of eddies is found to be approximately 40 days, and even if they are not apparent in the surface tracer maps (Fig. 9), they are the footprint of a characteristic free mode of the dynamical system [Eq. (5)]. This period is close to the one of the wave generation occurring a few degrees of latitude equatorward, and the Congo River inflow could be seen as a wave maker, exciting signals that modulate the spreading of low-salinity water. The geomorphology thus plays an important role in driving the near-field plume northward, then reaching the equatorial band where wave signals are dominating.

\section{c. Impact of other forcing}

Many studies have focused on the role of the wind on buoyant coastal currents and river plumes. The first numerical experiments were carried out by Chao (1988b), who concluded that the most important response was the wind-induced surface Ekman drift. Upwelling favorable winds cause the seaward excursion of the plume and tend to increase the vertical mixing and reduce stratification. Lentz (2004) developed a two-dimensional theory to

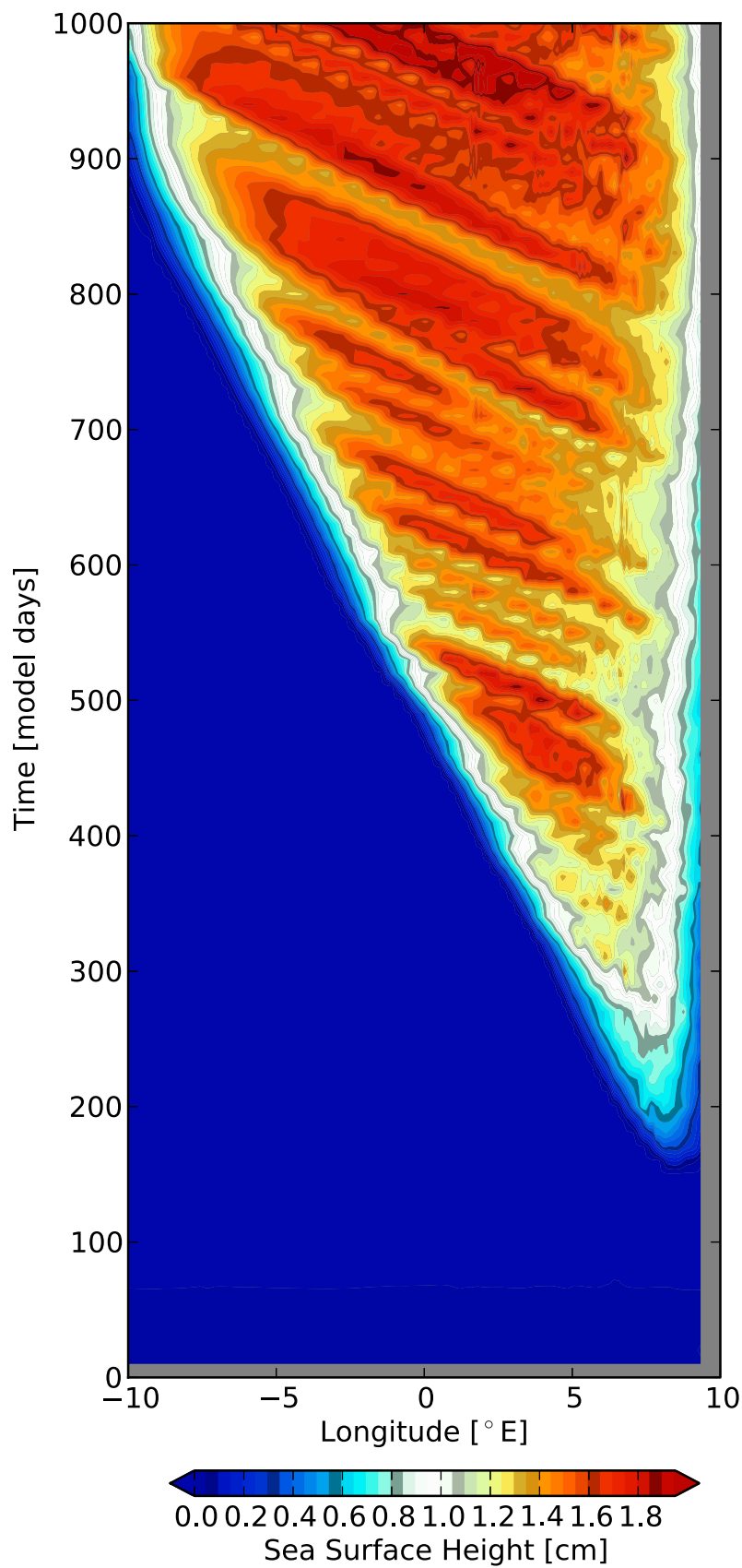

FIG. 10. Time-lon diagram of the SSH for the TOPO experiment at $2^{\circ} \mathrm{S}$.

quantify the effect of the wind on an existing plume by calculating the entrainment rate and the offshore drift of the coastal current

Figures $9 \mathrm{c}$ and $9 \mathrm{f}$ show the response of the plume to the steady wind field at 100 and 920 days of simulation. The wind-driven surface Ekman current at about $45^{\circ}$ to the left of the wind direction (Fig. 4) largely dominates the dynamics outside the plume. The plume core is 


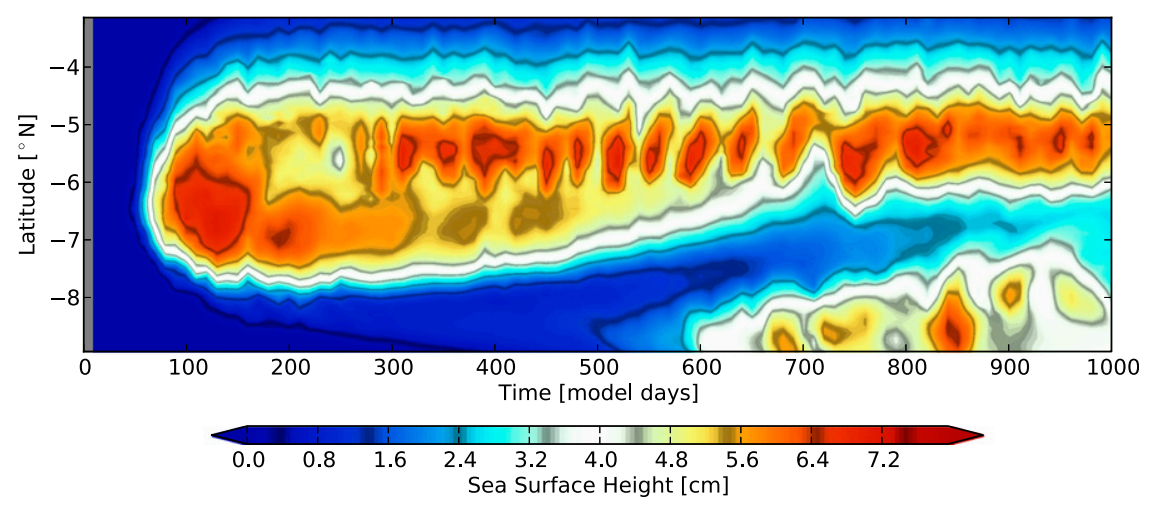

FIG. 11. Time-lat diagram of the SSH for the TOPO experiment at $10^{\circ} \mathrm{E}$.

transported northwestward under the influence of this Ekman drift (Chao 1988b). The salinity section of Fig. 7e does not represent the core of low-salinity water that is situated more northward, but we can notice the effect of containment of the plume height on the Ekman depth (Fong and Geyer 2001) $h_{\mathrm{Ek}}=(2 A /|f|)^{1 / 2}$, where $A$ is the vertical eddy diffusivity. With $A \approx 5 \times 10^{-3} \mathrm{~m}^{2} \mathrm{~s}^{-1}$ in the surface layers of the model in the plume area, we have $h_{\mathrm{Ek}} \approx 26 \mathrm{~m}$, not far from the WIND plume depth (Fig. 7). This constraint on the plume depth is mainly due to enhanced vertical mixing in the surface layer caused by the important horizontal velocity shear in the Ekman layer (Lentz 2004). This leads to a more homogeneous and shallow mixed layer than in the REF simulation.

The southward coastal current does not develop at all. This is brought to the fore in simulations of Chao (1988b) where the wind inhibits the development of the downstream coastal current that opposes the coastal northward geostrophic jet developed in response to the pressure gradient induced by the offshore Ekman drift. This is a plausible explanation for the weakness or absence of the southward coastal current (Fig. 1), even if seasonality is not explored in our study and is marked in this current extension (D13).

Although plume stratification changes between WIND and TOPO experiments, surface velocity fields are not much different in terms of direction (Fig. 9) in a strip containing most of the low-salinity waters (between $5^{\circ}$ and $1^{\circ} \mathrm{S}$ ). Indeed, even if the winds increase the velocity in this band by nearly $60 \%$, the mean current direction is deflected northward by only $13^{\circ}$. As such, we conclude on a reinforcement of the naturally buoyancy-driven circulation by the annually averaged winds.

An important seasonality of the plume axis and extent has been highlighted in remote sensing data (Hopkins et al. 2013) and is reproduced in simulations of D13, shown on their seasonally averaged salinity maps. This may be associated with the complex regional current variability in the plume vicinity (Stramma and Schott 1999; Lumpkin and Garzoli 2005) mainly presented through the South Equatorial Current, the Angola Current, and the Benguela Coastal Current. This issue is beyond the scope of our study, as we aim to simplify the framework to explore mechanisms.

\section{Discussion and concluding remarks}

The impact of the Congo River on the salinity field in the Gulf of Guinea has been described from observational datasets (Eisma et al. 1978; Signorini et al. 1999). Mechanisms that govern the low-salinity water transport were recently studied by D13, who concluded on a high impact of environmental factors such as the wind, the geomorphology of the coast, and the bottom topography on the plume dynamics. However, the buoyancy-driven dynamics of near-equatorial plumes at long time scales had never been explored for huge rates of flow.

In this article, we have situated the Congo River in a theoretical framework examining what kind of dynamics and plume morphology we could expect from the river parameters. We have confirmed that near-equatorial plumes are more likely to be surface trapped than midlatitude plumes (Yankovsky and Chapman 1997) and that the amount of freshwater would be mostly contained in the offshore bulge rather than in the narrow coastal current, in coherence with observations. The nonlinear outflow at long time scale is expected to shed eddies whose size and shedding period are almost determined by the river parameters (Nof et al. 2002b).

Our idealized numerical experiments agree with the theory regarding the near-field plume morphology. They reveal an unusual behavior of the plume at a long time scale that had not been explored before, that is, the shedding of eddies due to $\beta$. These eddies strongly interact with each other leading to the extent of a lowsalinity tongue far offshore of the river mouth. We 
believe that this is a characteristic feature of low-latitude outflow and is seemingly not observed in the midlatitude as the shedding period is longer and the drifting speed of eventually formed eddies is lower (Fig. 3).

The joint effect of $\beta$ (Nof et al. 2002b) and topography (Matano and Palma 2010) deflects the plume equatorward, roughly reproducing the observed (SMOS and GlobColour) tongue of low-salinity water during its most important extent. This extent can only be reproduced by taking into account the $\beta$ effect and could not have been observed with the $f$-plane assumption of most of the idealized simulations carried out before [even with the low Kelvin number near-equatorial experiments of Garvine (1999)]. The mechanisms governing this extent are twofold, developed through $\beta$ pulling of nonlinear structures (Nof and Pichevin 2001) and excitation of waves that propagate on the plume stratification (Nash and Moum 2005). This gives a new physical explanation of the equatorward extent of the Congo River plume that could be relevant to other near-equatorial rivers.

The impact of the wind is qualitatively comparable in our idealized simulations and in realistic simulations of D13 as the Ekman northwestward drift strengthens the buoyancy-driven circulation. The upwelling favorable winds act by impeding the southward development of the coastal current by setting a geostrophic current settled in the Ekman-induced low SSH at the coast. We have not evaluated the role of the ambient circulation on the plume or the seasonality of the winds, which can only be tested in realistic simulations to be compared with observations (D13). Because of the large scale of the plume and the complex circulation in the region (Stramma and Schott 1999), the basin-scale circulation is likely to influence the far field as commonly suggested. These issues could be explored in future high-resolution regional experiments to assess the mechanisms that drive the plume seasonality. For instance, Chang and Oey (2010) found a decrease in the eddy shedding of the Loop Current due to the winds.

In conclusion, we argue that the $\beta$-induced selfadvection of the plume is one of the mechanisms that could explain, in part, the nonintuitive development of the low-salinity Congo plume in the Gulf of Guinea. Our idealized model experiments complement the more realistic ones of D13 and provide a new theoretical explanation for the behavior observed in their complex simulations.

Acknowledgments. SMOS data were provided by the Laboratory of Spatial Oceanography, and simulations were performed at the computing center CAPARMOR (IFREMER). This work was supported by IFREMER,
Actimar, Total, and Mercator Ocean. A.-M. Treguier is supported by CNRS. X. Couvelard is supported by ANR Project COMODO (ANR-11-MONU-005). We appreciated discussion with Bernard Bourles (IRD) that helped linking theory with the reality of the Congo River and suggestions from Guillaume Roullet (UBO) about the wavelike dynamics. We thank two reviewers for insightful remarks and especially the first reviewer who pointed out the relevance of the Nof and Pichevin theory to the Congo plume.

\section{REFERENCES}

Boutin, J., N. Martin, X. Yin, J. Font, N. Reul, and P. Spurgeon, 2012: First assessment of SMOS data over open ocean: Part II-Sea surface salinity. IEEE Trans. Geosci. Remote Sens., 50, 1662-1675.

Carton, X., 2001: Hydrodynamical modeling of oceanic vortices. Surv. Geophys., 22, 179-263.

Chang, Y.-L., and L.-Y. Oey, 2010: Why can wind delay the shedding of loop current eddies? J. Phys. Oceanogr., 40, 24812495.

Chao, S., 1988a: River-forced estuarine plumes. J. Phys. Oceanogr., 18, 72-88.

, 1988b: Wind-driven motion of estuarine plumes. J. Phys. Oceanogr., 18, 1144-1166.

- , and W. Boicourt, 1986: Onset of estuarine plumes. J. Phys. Oceanogr., 16, 2137-2149.

Chapman, D. C., and S. J. Lentz, 1994: Trapping of a coastal density front by the bottom boundary layer. J. Phys. Oceanogr., 24, 1464-1479.

Coynel, A., P. Seyler, H. Etcheber, M. Meybeck, and D. Orange, 2005: Spatial and seasonal dynamics of total suspended sediment and organic carbon species in the Congo River. Global Biogeochem. Cycles, 19, GB4019, doi:10.1029/2004GB002335.

Dai, A., and K. Trenberth, 2002: Estimates of freshwater discharge from continents: Latitudinal and seasonal variations. J. Hydrometeor., 3, 660-687.

Denamiel, C., W. Budgell, and R. Toumi, 2013: The Congo River plume: Impact of the forcing on the far-field and near-field dynamics. J. Geophys. Res. Oceans, 118, 964-989, doi:10.1002/ jgrc. 20062 .

Eisma, D., and A. Van Bennekom, 1978: The Zaire River and estuary and the Zaire outflow in the Atlantic Ocean. Neth. J. Sea Res., 12, 255-272.

Fong, D., and W. Geyer, 2001: Response of a river plume during an upwelling favorable wind event. J. Geophys. Res., 106 (C1), 1067-1084.

— , and - 2002: The alongshore transport of freshwater in a surface-trapped river plume. J. Phys. Oceanogr., 32, 957-972.

Garvine, R., 1974: Dynamics of small-scale oceanic fronts. J. Phys. Oceanogr., 4, 557-569.

, 1999: Penetration of buoyant coastal discharge onto the continental shelf: A numerical model experiment. J. Phys. Oceanogr., 29, 1892-1909.

Haidvogel, D. B., and A. Beckmann, 1999: Numerical Ocean Circulation Modeling. Series on Environmental Science and Management, Vol. 344, Imperial College Press London, 300 pp.

Hopkins, J., M. Lucas, C. Dufau, M. Sutton, J. Stum, O. Lauret, and C. Channelliere, 2013: Detection and variability of the Congo River plume from satellite derived sea surface temperature, 
salinity, ocean colour and sea level. Remote Sens. Environ., 139, 365-385.

Jourdin, F., J. Froidefond, S. Loyer, C. Lefèvre, Y. Mayoyas, C. Vrignaud, and N. Kolodziejczyk, 2006: Measuring upper ocean turbidity off Congo and Gabon coasts. Proc. CMM'06 Caractérisation du Milieu Marin, Brest, France, SHOM.

Kao, T., C. Park, and H. Pao, 1977: Buoyant surface discharge and small-scale oceanic fronts: A numerical study. J. Geophys. Res., 82 (12), 1747-1752.

,-- , and - 1978: Inflows, density currents, and fronts. Phys. Fluids, 21, 1912-1922.

Kourafalou, V., L. Oey, J. Wang, and T. Lee, 1996: The fate of river discharge on the continental shelf: 1 . Modeling the river plume and the inner shelf coastal current. J. Geophys. Res., 101 (C2), 3415-3434.

Large, W. G., J. C. McWilliams, and S. C. Doney, 1994: Oceanic vertical mixing: A review and a model with a nonlocal boundary layer parameterization. Rev. Geophys., 32, 363-403.

Lentz, S., 2004: The response of buoyant coastal plumes to upwelling-favorable winds. J. Phys. Oceanogr., 34, 2458-2469.

Levitus, S., 1982: Climatological atlas of the world ocean. NOAA/ ERL GFDL Professional Paper 13, $173 \mathrm{pp}$

Lumpkin, R., and S. L. Garzoli, 2005: Near-surface circulation in the tropical Atlantic Ocean. Deep-Sea Res., 52, 495-518.

Marchesiello, P., L. Debreu, and X. Couvelard, 2009: Spurious diapycnal mixing in terrain-following coordinate models: The problem and a solution. Ocean Modell., 26, 156-169.

Maritorena, S., O. d'Andon, A. Mangin, and D. Siegel, 2010: Merged satellite ocean color data products using a bio-optical model: Characteristics, benefits and issues. Remote Sens. Environ., 114, 1791-1804.

Matano, R. P., and E. D. Palma, 2010: The upstream spreading of bottom-trapped plumes. J. Phys. Oceanogr., 40, 1631-1650.

Materia, S., S. Gualdi, A. Navarra, and L. Terray, 2012: The effect of Congo River freshwater discharge on eastern equatorial Atlantic climate variability. Climate Dyn., 39, 2109-2125.

Morrow, R., F. Birol, D. Griffin, and J. Sudre, 2004: Divergent pathways of cyclonic and anti-cyclonic ocean eddies. Geophys. Res. Lett., 31, L24311, doi:10.1029/2004GL020974.

Nash, J. D., and J. N. Moum, 2005: River plumes as a source of large-amplitude internal waves in the coastal ocean. Nature, 437, 400-403.

Nof, D., 1981: On the $\beta$-induced movement of isolated baroclinic eddies. J. Phys. Oceanogr., 11, 1662-1672.

, 2005: The momentum imbalance paradox revisited. J. Phys. Oceanogr., 35, 1928-1939.

— , and T. Pichevin, 2001: The ballooning of outflows. J. Phys. Oceanogr., 31, 3045-3058.

— Sea Res., 49, 1531-1549.

, T. Pichevin, and J. Sprintall, 2002b: "Teddies" and the origin of the Leeuwin Current. J. Phys. Oceanogr., 32, 2571-2588.
Penven, P., V. Echevin, J. Pasapera, F. Colas, and J. Tam, 2005: Average circulation, seasonal cycle, and mesoscale dynamics of the Peru Current system: A modeling approach. J. Geophys. Res., 110, C10021, doi:10.1029/2005JC002945.

Pichevin, T., and D. Nof, 1997: The momentum imbalance paradox. Tellus, 49A, 298-319.

Risien, C., and D. Chelton, 2008: A global climatology of surface wind and wind stress fields from eight years of QuikSCAT scatterometer data. J. Phys. Oceanogr., 38, 2379-2413.

Salisbury, J., D. Vandemark, J. Campbell, C. Hunt, D. Wisser, N. Reul, and B. Chapron, 2011: Spatial and temporal coherence between Amazon River discharge, salinity, and light absorption by colored organic carbon in western tropical Atlantic surface waters. J. Geophys. Res., 116, C00H02, doi:10.1029/ 2011JC006989.

Schiller, R., and V. Kourafalou, 2010: Modeling river plume dynamics with the hybrid coordinate ocean model. Ocean Modell., 33, 101-117.

Schlünz, B., and R. Schneider, 2000: Transport of terrestrial organic carbon to the oceans by rivers: Re-estimating flux- and burial rates. Int. J. Earth Sci., 88, 599-606.

Shchepetkin, A. F., and J. C. McWilliams, 2005: The regional oceanic modeling system (ROMS): A split-explicit, freesurface, topography-following-coordinate oceanic model. Ocean Modell., 9, 347-404.

Signorini, S. R., R. Murtugudde, C. McClain, J. Christian, J. Picaut, and A. Busalacchi, 1999: Biological and physical signatures in the tropical and subtropical Atlantic. J. Geophys. Res., 104 (C8), 18367-18382.

Smith, W., and D. Sandwell, 1997: Global sea floor topography from satellite altimetry and ship depth soundings. Science, 277, 1956-1962.

Stramma, L., and F. Schott, 1999: The mean flow field of the tropical Atlantic Ocean. Deep-Sea Res., 46, 279-303.

Sutherland, D., and C. Cenedese, 2009: Laboratory experiment on the interaction of a buoyant coastal current with a canyon: Application to the East Greenland Current. J. Phys. Oceanogr., 39, 1258-1271.

Sutyrin, G. G., and G. R. Flierl, 1994: Intense vortex motion on the beta plane: Development of the beta gyres. J. Atmos. Sci., 51, 773-790.

Theiss, J., 2004: Equatorward energy cascade, critical latitude, and the predominance of cyclonic vortices in geostrophic turbulence. J. Phys. Oceanogr., 34, 1663-1678.

Vangriesheim, A., C. Pierre, A. Aminot, N. Metzl, F. Baurand, and J. Caprais, 2009: The influence of Congo River discharges in the surface and deep layers of the Gulf of Guinea. Deep-Sea Res., 56, 2183-2196.

Verstraete, J., 1992: The seasonal upwellings in the Gulf of Guinea. Prog. Oceanogr., 29, 1-60.

Yankovsky, A., and D. Chapman, 1997: A simple theory for the fate of buoyant coastal discharges. J. Phys. Oceanogr., 27, 1386-1401. 